\title{
HOW MANY STANDARDS IN A LAPTOP? (AND OTHER EMPIRICAL QUESTIONS)
}

\author{
Brad Biddle, Andrew White and Sean Woods
}

Arizona State University Sandra Day O’Connor College of Law

\begin{abstract}
An empirical study which identifies 251 technical interoperability standards implemented in a modern laptop computer, and estimates that the total number of standards relevant to such a device is much higher. Of the identified standards, the authors find that $44 \%$ were developed by consortia, $36 \%$ by formal standards development organizations, and $20 \%$ by single companies. The intellectual property rights policies associated with 197 of the standards are assessed: $75 \%$ were developed under "RAND" terms, 22\% under "royalty free" terms, and 3\% utilize a patent pool. The authors make certain observations based on their findings, and identify promising areas for future research.
\end{abstract}

Keywords - standards, SDOs, consortia, intellectual property rights (IPR), RAND, royalty free

\section{OVERVIEW}

Our effort began with some simple questions: how many standards are embodied in a modern laptop computer? How many of these standards are developed by formal standards development organizations and how many by consortia? What type of intellectual property rights policies - e.g. "RAND" or "royalty-free" - apply to each of these standards?

Answering these seemingly-simple questions proved dauntingly complex. Nonetheless, subject to the limitations and qualifications described in this paper, we were able to reach the following conclusions:

- We identified 251 interoperability standards that are

Brad Biddle is an Adjunct Professor at ASU and Standards Counsel for Intel Corporation; Andrew White and Sean Woods are law students. This article reflects the authors' personal views. The authors thank Steve Balogh, Carl Cargill, Wayne Carr, Kevin Cornelius, Bob Grow, Earl Nied, Ken Salzberg, Kim Turner, Steve Whalley and Andrew Wilson for their invaluable input. Errors are solely the responsibility of the authors.

Paper accepted for presentation at the ITU-T "Beyond the Internet? Innovations for future networks and services" Kaleidoscope Conference, Pune, India, http://itu-kaleidoscope.org/2010, and will be published in the conference proceedings. This version of the paper is considered final. It was completed on September 10, 2010 and supersedes a draft dated May 7, 2010. Suggested citation: "Biddle, Brad, White, Andrew and Woods, Sean, How Many Standards in a Laptop? (And Other Empirical Questions) (September 10, 2010). Available at SSRN: http://ssrn.com/abstract=1619440." embodied or directly utilized in a modern laptop computer. We focused only on standards that facilitate technical interoperability, and did not count quality, safety, performance, measurement, environmental, accessibility, design process, manufacturing process or electromagnetic compatibility standards. Further, our count of interoperability standards is not comprehensive: we have become aware of significant omissions. Accordingly, we believe our count sets only a floor: a modern laptop embodies or utilizes at least 251 interoperability standards, but the actual number is certainly much higher (the authors would be unsurprised by a total number of 500 or more). Including other types of relevant standards, such as environmental or safety standards, in addition to interoperability standards would further raise the count dramatically.

- Of the 251 standards we identified, 112 (44\%) were developed by consortia, $90(36 \%)$ by formal standards development organizations, and $49(20 \%)$ by individual companies (see Figure 1).

- We were able to allocate 197 of the 251 standards into one of three broad intellectual property model categories: RAND, RF or patent pool (we lacked sufficient information to categorize the remaining 54 standards). Of the 197 we categorized, 148 (75\%) were RAND, 43 (22\%) were RF, and $6(3 \%)$ utilized a patent pool (see Figure 2).

In order to meaningfully assess our data it is imperative that readers understand our terminology and our methodology. These are described in Section 2, below. Section 3 highlights some limitations of our approach, and identifies some gaps in our research. Section 4 explores some preliminary observations and conclusions based on our data. Section 5 identifies opportunities for further research. Finally, the appendix contains a table listing the particular standards we identified and the values we assigned to each.

\section{TERMINOLOGY AND METHODOLOGY}

We began by examining the specifications of various current-generation laptop computers produced by different manufacturers, and developing a vision of a composite, hypothetical laptop that drew from the features of each. We also gave ourselves some flexibility to include a few features that are widely expected to be included in laptops in the imminent future (e.g. hi-definition wireless display capabilities). 
Next, we created a set of broad categories - display, graphics, sound, storage, BIOS, input device, processor, power, file system, networking, wireless, I/O ports, memory, software, codecs, content protection, security and "other" - and sought relevant standards. Using a variety of methods, including interviews with experts and extensive primary research, we identified standards in each category that would be embodied in or directly utilized by our hypothetical laptop computer.

For our purposes, "standards" included not just standards developed by formal standards development organizations like ISO, but also industry specifications developed by consortia like PCI-SIG. We also encountered a number of specifications intentionally promulgated by a single company for broader industry adoption, and we counted these as "standards" as well. We limited our count of company-promulgated standards to those that a company intentionally and specifically made available for adoption as an industry specification; we did not include proprietary technologies that have significant market share but that are not otherwise intentionally made available for industry adoption.

As noted in the introduction, we focused only on standards that facilitate technical interoperability, and did not count quality, safety, performance, measurement, environmental, accessibility, design process, manufacturing process or electromagnetic compatibility standards.

We identified the developer/promoter of each standard as either (a) a formal standards development organization or "SDO," (b) a consortium, or (c) an individual company. For this step we utilized the taxonomy suggested by the IPO Standards Setting Committee in their 2009 "Standards Primer" document. [1] We counted as SDOs: (a) the "Big I" international standards organizations (ITU, ISO, IEC), (b) the "Little I" international organizations (IEEE, ASTM), (c) government-sanctioned regional bodies such as ETSI, (d) government-sanctioned national bodies, such as BSI, and (e) organizations sanctioned or accredited by a national body, such as all of the ANSI-accredited organizations (e.g., JEDEC, TIA). All other group-focused specificationdevelopment efforts were classified as "Consortia." The consortia category contains a wide variety of different groups, ranging from formal organizations like the $\mathrm{W} 3 \mathrm{C}$ to very informal open source development efforts. We called specifications created by single commercial entity "Company" standards.

Assessing the intellectual property rights (IPR) policies associated with each standard proved difficult. Many IPR policies were extraordinarily complex. Further, IPR policies for some organizations were not publicly available, leaving us to rely on second-hand accounts or draw inferences. Noting some risk of oversimplification or error, we allocated each standard to one of four broad categories:

- RAND. This category included standards that were developed under RAND or F/RAND terms - (fair,) reasonable and non-discriminatory patent license commitments, without precluding the option of patent owners collecting patent royalties for essential patent claims. If a SDO or Consortia permitted a RAND option, even if it contemplated other options as well, we included it in the RAND category. We note that the fact that an IPR policy permits collection of royalties does not mean that parties in fact collect royalties. (IETF provides an example: the IETF IPR policy permits RAND, and thus we categorized all IETF standards as RAND, but in practice parties attempt to collect royalties on few, if any, IETF standards.)

- $R F$. This category included standards that were created under terms that prohibit the participating companies or individuals from collecting patent royalties for essential patent claims (usually subject to important limitations). For our purposes, IPR models such as "RF-RAND" (royalty-free RAND) and "RAND-Zero" (RAND with zero royalties) fall into this category. We also included standards with IPR policies that rely on promises not to assert essential patent claims here. Note that our designation of a standard as RF does not mean that the standard is in fact royalty free to implement, as entities not bound by the IPR policy could assert patents, for example.

- Patent pool. The term "patent pool" is sometimes defined in a way that would sweep in virtually any RAND or RF IPR policy, but for our purposes we adopted a narrow definition. We focused on the scenario where a specification is made available subject to execution of a license agreement, and that license agreement conveys a license to patents pooled by multiple parties. The DVD specifications provide an example.

- NA ("not available"). In 54 of our 251 cases we simply could not determine the intellectual property policy associated with a particular standard. Figure 2 below includes only the 197 bodies that we were able to categorize.

We should emphasize that our taxonomy glosses over a great deal of complexity, including the key issue of whether the RAND or RF promise extends from participants in the standards development process to all implementers or only to those implementers that join the relevant consortia or SDO. For our categorization purposes, either approach sufficed: e.g., if a group required that participants promise to license on RAND terms only to members of that group, with no other license obligation, we counted that group as RAND.

\section{LIMITATIONS AND GAPS}

Our hypothetical/composite laptop approach potentially allows some ambiguity or duplication. For example, we include file systems standards for both Linux and Windows computers, even though in many cases they would not coexist in a single machine. Likewise, we include wireless display standards that might be competitive rather than co- 
existing. Focusing on a single, specific "real world" machine would have mitigated this risk. However, our composite approach enabled us to avoid singling out a specific vendor, and enabled us to anticipate soon-to-be implemented standards.

A related point: while our primary focus was on standards that would be fully implemented in our hypothetical laptop, we also included some standards that would be directly used by our hypothetical machine, but that are not necessarily fully implemented on the client side (e.g., basic Internet standards like IPv4, DNS or TCP). This involved some judgment calls and line drawing. Similarly, we included standards related to some basic software applications (e.g., OpenXML), but tried to avoid expanding too far "up the stack" into the software application world.

Another issue: our data are imperfect. The authors bring legal expertise to the table rather than deep technical expertise. Understanding each of our various technical focus areas - display, graphics, sound, storage, BIOS, input device, processor, power, file system, networking, wireless, I/O ports, memory, software, codecs, content protection, security - sufficiently to assess the relevant standards in each area proved challenging. We suspect there are errors of both under-inclusion and over-inclusion in some of our focus areas. Further, we have realized that our focus areas may have been too narrow. For example, battery technologies, biometrics, camera hardware, solid state drives and docking systems standards are currently underrepresented in our list. We will continue to refine and improve the quality of our data set. However, we do not believe that this refinement will dramatically change our observations or conclusions.

\section{OBSERVATIONS}

The focus of this stage of our effort has been primarily on collecting empirical data rather than interpreting it. However, a set of fairly obvious conclusions are immediately apparent:

- $\quad$ The critical role of standards in ICT. The fact that a modern laptop computer implements or relies on over 250 (and probably closer to 500, we estimate) interoperability standards is remarkable. While certainly no one doubted the importance of standards to the information and communications technology (ICT) industry in the absence of this data, quantifying the volume of standards embodied in a common ICT device is striking. We believe that as technological convergence continues, and ICT devices increasing include elements from the computing, telephony and consumer electronics sectors, the number of relevant standards will only increase.

- The importance of consortia for ICT standards development. Of the 251 standards we indentified, only about one-third were developed by formal SDOs. Consortia developed 44\%, and single companies developed $20 \%$ (see Figure 1). We suspect the dominant role played by the private sector in at least this aspect of ICT standardization will come as a surprise to some policymakers and other standardization stakeholders.

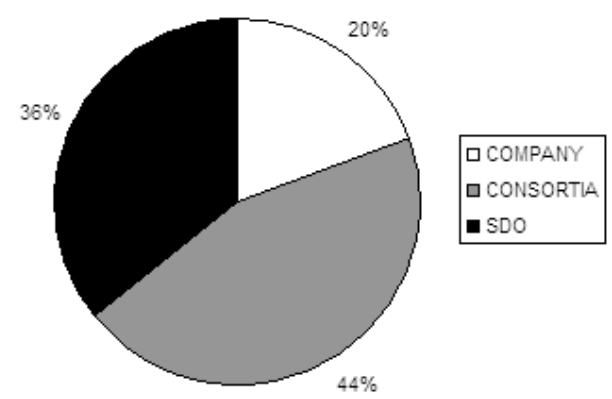

Figure 1: TYPE OF STAIIDARD/SPEC DEVELOPER

- The preponderance of RAND as IPR model. The merits of RAND and RF IPR models are fiercely debated by their respective proponents. Our data suggests that historically RAND has been effective in the computing sector, if measured by implementation of associated standards: we see that $75 \%$ of the standards we examined were developed under RAND terms (see Figure 2). Conceivably the financial industry axiom that "past performance is not indicative of future results" may be applicable, given the emergence of open source, increasing patent litigiousness, or other factors. Further, the practical impact of RAND policies seems to be different in different contexts (e.g., IETF standards, while nominally RAND, appear to be largely $\mathrm{RF}$ in practice; other RAND standards, such as the IEEE's 802.11 standards, are the subject of licensing and patent litigation). Nonetheless, the strong dominance of RAND in our set of successful (i.e., implemented) standards is notable. Our data also suggest that patent pools, to date, have not played a significant role for at least the computing sector of the ICT industry.

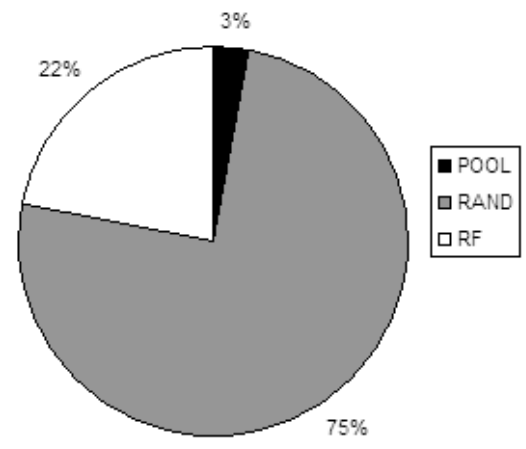

Figure 2: IP MODELS 


\section{NEXT STEPS AND CONCLUSION}

As noted in Section 3 above, a key next step for us is to expand our data set and refine our data. We welcome constructive input and will happily make our spreadsheets available to interested parties.

While we utilized a single RAND category, we have noted that in the ICT environment there seems to be two broad subcategories of RAND standards: those for which the de facto reality seems to be a RF environment, and those for which there are active royalty-collection efforts. We believe that it would be interesting to attempt to count the number of standards in each subcategory.

Another promising focus area for additional empirical analysis is an assessment of consortia. For our purposes consortia occupied a single category, but in fact we saw a bewildering variety of approaches among consortia in the course of our research. Identifying different types of consortia, and analyzing the implementation of standards produced by different types, strikes us as a fascinating research question.

Additionally, assessing each of our identified standards against various criteria of "openness," along the lines of Per Anderson's recent study [2], could prove quite interesting. Our working theory is that the development and distribution processes associated with a significant percentage of the successfully-implemented standards we identified would not meet typical definitions of openness, transparency or consensus decision-making. If true, this would be an interesting data point to bring into, e.g., current policy debates over "good practices" for consortia, such as the current BSI PAS 98 effort. Further, it would be interesting to consider whether the empirical data could demonstrate either a positive or negative correlation between the "openness" of a standards development effort and its effectiveness as measured by widespread implementation of that standard in the commercial marketplace.

The academic literature on standardization often bemoans the dearth of empirical analysis of standards. Our hope is that the analysis documented in this paper helps to fill this gap, and enables policymakers, academics, commercial stakeholders and others to better understand ICT standards and industry specifications.

\section{REFERENCES}

[1] IPO Standards Setting Committee, Standards Primer: An Overview of Standards Setting Bodies and PatentRelated Issues that Arise in the Context of Standards Setting Activities, 2009 IPO Articles \& Reps., Pats. Sec. No. 16 (10/09/2009). Available to IPO members via http://ipo.org; excerpts publicly available at $<$ http://standardslaw.org/seminar/class-2/excerpts-from-ipostandards-primer/>.

[2] Per Anderson, Evaluation of Ten Standard Setting Organizations With Regard to Open Standards, IDC Study commissioned by the Danish National IT and Telecom Agency, January 2008. Available at <http://www.itst.dk/itarkitektur-og-standarder/standardisering/abne-

standarder/baggrundsrapporter/Evaluation $\% 20$ of $\% 20 \mathrm{Ten} \%$ 20Standard\%20Setting\%20Organizations.pdf $>$. 
APPENDIX:

LIST OF STANDARDS/SPECIFICATIONS

\begin{tabular}{|c|c|c|c|c|c|c|c|}
\hline $\begin{array}{c}\text { Name of } \\
\text { standard/specification }\end{array}$ & Developer & $\begin{array}{l}\text { Developer } \\
\text { type }\end{array}$ & $\begin{array}{c}\text { IP } \\
\text { type }\end{array}$ & $\begin{array}{c}\text { Name of } \\
\text { standard/specification }\end{array}$ & Developer & $\begin{array}{l}\text { Developer } \\
\text { type }\end{array}$ & $\begin{array}{c}\text { IP } \\
\text { type }\end{array}$ \\
\hline NET & Microsoft & COMPANY & NA & DirectX & Microsoft & COMPANY & NA \\
\hline $\begin{array}{l}\text { 16x9 Notebook Panel ver. } \\
\text { 1a }\end{array}$ & VESA & CONSORTIA & RAND & $\begin{array}{l}\text { Display Identification Data } \\
\text { [DisplayID] Structure v1.1 }\end{array}$ & VESA & CONSORTIA & RAND \\
\hline $3 \mathrm{GP}$ & 3GPP & SDO & RAND & \multirow{3}{*}{$\begin{array}{l}\text { Display Port Panel } \\
\text { Connector } \\
\text { Display Subsystem Power } \\
\text { Management }\end{array}$} & \multirow[t]{2}{*}{ VESA } & \multirow[t]{2}{*}{ CONSORTIA } & \multirow[t]{2}{*}{ RAND } \\
\hline 8P8C/"RJ-45" IEC 60603 & IEC & SDO & RAND & & & & \\
\hline AC'97 v2.3 & Intel & COMPANY & NA & & VESA & CONSORTIA & RAND \\
\hline $\begin{array}{l}\text { ACS-2 [ATA/ATAPI } \\
\text { Command Set 2] }\end{array}$ & T13 INCITS & SDO & RAND & \multirow{2}{*}{$\begin{array}{l}\text { DisplayPort } \\
\text { Interoperability Guidline } \\
\text { v1.1 }\end{array}$} & \multirow[t]{2}{*}{ VESA } & \multirow[t]{2}{*}{ CONSORTIA } & \multirow[t]{2}{*}{ RAND } \\
\hline Advanced Configuration & \multirow[t]{2}{*}{ ACPI } & \multirow[t]{2}{*}{ CONSORTIA } & \multirow[t]{2}{*}{ RAND } & & & & \\
\hline $\begin{array}{l}\text { and Power Interface Spec } \\
3.0\end{array}$ & & & & DLNA & $\begin{array}{l}\text { Digital Living } \\
\text { Network }\end{array}$ & CONSORTIA & RAND \\
\hline Advanced eXpress I/O & \multirow[t]{2}{*}{ ATI } & \multirow[t]{2}{*}{ COMPANY } & \multirow[t]{2}{*}{ NA } & & Alliance & & \\
\hline Module [AXIOM] & & & & \multirow{2}{*}{$\begin{array}{l}\text { DMI2 [Direct Media } \\
\text { Interface] }\end{array}$} & \multirow[t]{2}{*}{ Intel } & \multirow[t]{2}{*}{ COMPANY } & \multirow[t]{2}{*}{ NA } \\
\hline AES (U.S. FIPS PUB 197) & NIST & SDO & NA & & & & \\
\hline AGP & Intel & COMPANY & NA & DNS & IETF & CONSORTIA & RAND \\
\hline AIFF & Apple & COMPANY & NA & DOM & W3C & CONSORTIA & $\mathrm{RF}$ \\
\hline ALC889 & RealTek & COMPANY & NA & DVB-H/EN 302304 & DVB/ETSI & SDO & RAND \\
\hline Allegro 4.9.19 & open source & CONSORTIA & RF & DVD Multi & DVD Forum & CONSORTIA & POOL \\
\hline & project & & & DVI & DDWG & CONSORTIA & RAND \\
\hline $\begin{array}{l}\text { ANSI INCITS 207- } \\
\text { 1991[R2007] }\end{array}$ & ANSI & SDO & RAND & DVI 1.0 Spec & $\begin{array}{l}\text { Digital } \\
\text { Display }\end{array}$ & CONSORTIA & NA \\
\hline $\begin{array}{l}\text { ANSI INCITS 346- } \\
2001[\mathrm{r} 2006]\end{array}$ & ANSI & SDO & RAND & & $\begin{array}{l}\text { Working } \\
\text { Group }\end{array}$ & & \\
\hline ANSI INCITS 407-2005 & ANSI & SDO & RAND & ECMA 262 3rd edition & ECMA & CONSORTIA & RAND \\
\hline ANSI INCITS 417-2006 & ANSI & SDO & RAND & ECMA C\# & ECMA & CONSORTIA & RAND \\
\hline APM & Microsoft & COMPANY & NA & ECMA CLR & ECMA & CONSORTIA & RAND \\
\hline ASF & Microsoft & COMPANY & NA & ECMA-378 & ECMA & SDO & RAND \\
\hline Atom & IETF & CONSORTIA & RAND & ECMA-384 & ECMA & SDO & RAND \\
\hline AVI & Microsoft & COMPANY & NA & EDD-4 [Enhanced Disk & T13 INCITS & SDO & RAND \\
\hline Bluetooth spec. & Bluetooth Sig & CONSORTIA & $\mathrm{RF}$ & Drive - 4 & & & \\
\hline Blu-ray Disc Read-Only & Blu-ray Disc & CONSORTIA & POOL & EHCI & Intel & COMPANY & NA \\
\hline Format ver. 1 & Association & & & Embedded DisplayPort & VESA & CONSORTIA & RAND \\
\hline Blu-ray Disc Recordable & Blu-ray Disc & CONSORTIA & POOL & Standard (eDP) & & & \\
\hline Format ver. 1 & Association & & & Ethernet [802.3] & IEEE & SDO & RAND \\
\hline $\begin{array}{l}\text { Blu-ray Disc Rewrittable } \\
\text { Fromat ver. } 2\end{array}$ & $\begin{array}{l}\text { Blu-ray Disc } \\
\text { Association }\end{array}$ & CONSORTIA & POOL & EXT4 & open source & CONSORTIA & $\mathrm{RF}$ \\
\hline $\mathrm{C}$ & ANSI/ISO & SDO & RAND & Fat16 & ECMA & SDO & RAND \\
\hline $\begin{array}{l}\mathrm{C}++(\mathrm{ISO} / \mathrm{IEC} \\
14882: 2003)\end{array}$ & ISO/IEC & SDO & RAND & Fat32 & $\begin{array}{c}\text { Microsoft } \\
\text { [Open Spec] }\end{array}$ & COMPANY & NA \\
\hline CD audio ("Red book") - & IEC & SDO & RAND & Firewire/1394 & IEEE & SDO & RAND \\
\hline IEC 60908 & & & & Flash (FLV, F4V) & Adobe & COMPANY & NA \\
\hline CDROM & ISO/IEC & SDO & RAND & FMOD & Firelight & COMPANY & NA \\
\hline CIM [Common & DMTF & CONSORTIA & RAND & & Technologies & & \\
\hline Information Model] 2.250 & & & & FTP & IETF & CONSORTIA & RAND \\
\hline Cinepak & $\begin{array}{c}\text { SuperMac } \\
\text { Technologies }\end{array}$ & COMPANY & NA & $\begin{array}{l}\text { Guidline for transmission } \\
\text { and control for DVD- }\end{array}$ & DVD Forum & CONSORTIA & POOL \\
\hline COLLADA 1.5 & Khronos & CONSORTIA & $\mathrm{RF}$ & video/audio through & & & \\
\hline Compact Flash & Compact & CONSORTIA & RAND & IEEE1394 Bus & & & \\
\hline & Flash Ass. & & & Guidline for Transmission & DVD Forum & CONSORTIA & POOL \\
\hline $\begin{array}{l}\text { CSS (Cascading Style } \\
\text { Sheet) }\end{array}$ & W3C & CONSORTIA & $\mathrm{RF}$ & $\begin{array}{l}\text { and Control for DVD- } \\
\text { video/audio through Most }\end{array}$ & & & \\
\hline CSS (Content Scramble & DVD Forum & CONSORTIA & NA & Bus & & & \\
\hline System) & & & & Н.263 & ITU-T & SDO & RAND \\
\hline DDR3 & JEDEC & SDO & RAND & H.264 & ITU- & SDO & RAND \\
\hline Dirac & $\begin{array}{c}\text { BBC } \\
\text { Research }\end{array}$ & COMPANY & RF & & $\begin{array}{l}\text { T/ISO/IEC } \\
\text { JVT }\end{array}$ & & \\
\hline Direct Drive Monitor & VESA & CONSORTIA & RAND & $\mathrm{HDCP}$ & DCP & COMPANY & NA \\
\hline$[\mathrm{DDM}] \mathrm{v} 1$ & & & & HDMI & HDMI & CONSORTIA & RAND \\
\hline Direct3D 11 & Microsoft & COMPANY & NA & HFS & Apple & COMPANY & NA \\
\hline
\end{tabular}




\begin{tabular}{|c|c|c|c|c|c|c|c|}
\hline HFS+ & Apple & COMPANY & NA & ISO/IEC 24739-1:2009 & ISO & SDO & RAND \\
\hline HTML5 & W3C & CONSORTIA & $\mathrm{RF}$ & ISO/IEC 24739-2:2009 & ISO & SDO & RAND \\
\hline HTTP & W3C & CONSORTIA & $\mathrm{RF}$ & ISO/IEC 24739-3:2009 & ISO & SDO & RAND \\
\hline HTTPS & $\mathrm{W} 3 \mathrm{C}$ & CONSORTIA & $\mathrm{RF}$ & ISO/IEC 24757:2008 & ISO & SDO & RAND \\
\hline HuffYUV & Rudiak-Gould & COMPANY & NA & ISO/IEC 26300:2006 Open & ISO/IEC & SDO & RAND \\
\hline IEC 60320 & IEC & SDO & RAND & Document Format & & & \\
\hline IEC 60958 type II (S/PIF) & IEC & SDO & RAND & ISO/IEC 29121:2009 & ISO & SDO & RAND \\
\hline IEEE std. 1212.1-1993 & IEEE & SDO & RAND & ISO/IEC 29171:2009 & ISO & SDO & RAND \\
\hline IEEE std. 1680.1-2009 & IEEE & SDO & RAND & $\begin{array}{l}\text { ISO/IEC 29171:2009 } \\
\text { [iVDR spec] }\end{array}$ & ISO & SDO & RAND \\
\hline IETF RFC 5545 iCalendar & IETF & CONSORTIA & RAND & ISO/IEC 29500 Office & ISO/IEC & SDO & RAND \\
\hline IMAP & IETF & CONSORTIA & RAND & Open XML & ISO & $\mathrm{SDO}$ & \\
\hline INCITS 370-2004(1510D): & T13 INCITS & SDO & RAND & 1SU/IEC 9995-1:2009 & ISO & SDU & RAND \\
\hline $\begin{array}{l}\text { ATA Host Adapter } \\
\text { Standards }\end{array}$ & & & & ISO/IEC 9995-3:202 & ISO & SDO & RAND \\
\hline INCITS 437-2008 & ISO & SDO & RAND & ISO/IEC 9995-4:2009 & ISO & SDO & RAND \\
\hline INCITS 452-2008(D1699): & T13 INCITS & SDO & RAND & ISO/IEC 9995-5:2009 & ISO & SDO & RAND \\
\hline ATA/ATAPI Command & & & & ISO/IEC 9995-7:2009 & ISO & SDO & RAND \\
\hline & & & & ISO/IEC 9995-8:2009 & ISO & SDO & RAND \\
\hline $\begin{array}{l}\text { Intel } 64 \text { architecture } \\
\text { x2APIC Spec }\end{array}$ & Intel & COMPANY & NA & ISO/IEC TR 24784:2009 & ISO & SDO & RAND \\
\hline Intel AHCI & Intel & COMPANY & NA & ISO/IEC TR29106:2007 & ISO/IEC & SDO & RAND \\
\hline Intel High Definition & Intel & COMPANY & NA & ISO 32000-1:2008 & ISO & SDO & RAND \\
\hline Audio & & & & JCP JSR 270 Java SE 6 & Java & CONSORTIA & RF \\
\hline $\begin{array}{l}\text { Intel Platform Innovation } \\
\text { Framework for UEFI }\end{array}$ & Intel & COMPANY & RAND & & $\begin{array}{l}\text { Community } \\
\text { Process }\end{array}$ & & \\
\hline IPSEC & IETF & CONSORTIA & RAND & Magsafe & Apple & COMPANY & NA \\
\hline $\mathrm{IPv} 4$ & IETF & CONSORTIA & RAND & MATHML & $\mathrm{W} 3 \mathrm{C}$ & CONSORTIA & $\mathrm{RF}$ \\
\hline ISO 8601 is dates and time & ISO/IEC & SDO & RAND & Matroska & open source & CONSORTIA & $\mathrm{RF}$ \\
\hline ISO 9241-300:2008 & ISO & SDO & RAND & & project & & \\
\hline ISO 9241-302:2008 & ISO & SDO & RAND & MD5 (RFC 1321) & IETF & CONSORTIA & RAND \\
\hline ISO 9241-303:2008 & ISO & SDO & RAND & Micro SD & $\begin{array}{c}\text { SD } \\
\text { Association }\end{array}$ & CONSORTIA & RAND \\
\hline ISO 9241-304:2008 & ISO & SDO & RAND & MIDI & MIDI & CONSORTIA & NA \\
\hline ISO 9241-305:2008 & ISO & SDO & RAND & & $\begin{array}{l}\text { Manufacturer } \\
\text { s Ass'n }\end{array}$ & & \\
\hline ISO 9241-306:2008 & ISO & SDO & RAND & MIME & IETF & CONSORTIA & RAND \\
\hline ISO 9241-307:2008 & ISO & SDO & RAND & Mini Displayport & VESA & CONSORTIA & $\mathrm{RF}$ \\
\hline ISO 9241-400:2007 & ISO & SDO & RAND & MINI-DVI & Apple & COMPANY & NA \\
\hline ISO 9241-400:2007 & ISO/IEC & SDO & RAND & MiniSD & SD & CONSORTIA & RAND \\
\hline ISO 9241-410:2008 & ISO & SDO & RAND & & Association & & \\
\hline ISO 9241-410:2008 & ISO/IEC & SDO & RAND & MJPEG (RFC 2435) & IETF & CONSORTIA & RAND \\
\hline $\begin{array}{l}\text { ISO/IEC } 1064 \text { is Unicode } \\
\text { (and uft- } 8 \text {, utf-16) }\end{array}$ & ISO/IEC & SDO & RAND & MMS & $\begin{array}{l}\text { Open Mobile } \\
\text { Alliance }\end{array}$ & CONSORTIA & RAND \\
\hline ISO/IEC 11002:2008 & ISO & SDO & RAND & $\begin{array}{l}\text { Monitor Control } \\
\text { Command Set [MCCS] }\end{array}$ & VESA & CONSORTIA & RAND \\
\hline ISO/IEC 11989:2010 & ISO & SDO & RAND & Standard v2.2 & & & \\
\hline ISO/IEC 13170:2009 & ISO & SDO & RAND & MP3 (MPEG-1 Layer 3) & ISO/IEC & SDO & RAND \\
\hline ISO/IEC 14772-2:2004 & ISO & SDO & RAND & $\begin{array}{l}\text { MP4 (ISO/IEC 14496- } \\
14 \cdot 2003 \text { ) }\end{array}$ & ISO/IEC & SDO & RAND \\
\hline ISO/IEC 14776-150:2004 & ISO & SDO & RAND & $\begin{array}{l}\text { 14:2003) } \\
\text { MPEG-2 }\end{array}$ & ISO/IEC & SDO & RAND \\
\hline ISO/IEC 15412:1999 & ISO & SDO & RAND & MPEG-2 (ISO/IEC 13818) & ISO/IEC & SDO & RAND \\
\hline ISO/IEC 15948:2004 & ISO & SDO & RAND & MPEG-4 Part 2 (ISO/IEC & ISO/IEC & SDO & RAND \\
\hline ISO/IEC 19774:2006 & ISO & SDO & RAND & $14496-2)$ & & & \\
\hline ISO/IEC 19775-1:2008 & ISO & SDO & RAND & MSFT Silverlight & Microsoft & COMPANY & NA \\
\hline ISO/IEC 19775-2:2004 & ISO & SDO & RAND & MXF & SMPTE & CONSORTIA & NA \\
\hline ISO/IEC 19776-1:2008 & ISO & SDO & RAND & MXM Graphic Module & MXM & CONSORTIA & $\mathrm{RF}$ \\
\hline ISO/IEC 19776-2:2008 & ISO & SDO & RAND & $\begin{array}{l}\text { Software Spec } 3.0 \text { revision } \\
1.1\end{array}$ & Group/SIG & & \\
\hline ISO/IEC 19776-3:2007 & ISO & SDO & RAND & MXM Graphics Module & MXM & CONSORTIA & $\mathrm{RF}$ \\
\hline ISO/IEC 19777-1:2006 & ISO & SDO & RAND & $\begin{array}{l}\text { Mobile PCI Express } \\
\text { Module Electromechanical }\end{array}$ & Group/SIG & & \\
\hline ISO/IEC 19777-2:2006 & ISO & SDO & RAND & Spec version 3.0 rev 1.1 & & & \\
\hline
\end{tabular}




\begin{tabular}{|c|c|c|c|c|c|c|c|}
\hline Net2Display Remoting & VESA & CONSORTIA & RAND & Sorenson & Sorenson & COMPANY & NA \\
\hline Standard (N2D) & \multirow[b]{2}{*}{$\begin{array}{c}\text { Microsoft } \\
\text { [Closed Spec] }\end{array}$} & \multirow{2}{*}{ COMPANY } & \multirow{2}{*}{ NA } & \multirow{2}{*}{$\begin{array}{l}\text { SQL - ISO/IEC } 9075 \\
\text { SVCD (IEC 62107) }\end{array}$} & \multirow{2}{*}{$\begin{array}{l}\text { ISO/IEC } \\
\text { IEC }\end{array}$} & \multirow{2}{*}{$\begin{array}{l}\text { SDO } \\
\text { SDO }\end{array}$} & \multirow{2}{*}{$\begin{array}{l}\text { RAND } \\
\text { RAND }\end{array}$} \\
\hline NTFS & & & & & & & \\
\hline \multirow{2}{*}{$\begin{array}{l}\text { NTP (time } \\
\text { synchronization) } \\
\text { OGG }\end{array}$} & IETF & CONSORTIA & RAND & SVG & W3C & CONSORTIA & $\mathrm{RF}$ \\
\hline & Xiph.Org & CONSORTIA & $\mathrm{RF}$ & $\begin{array}{l}\text { TCG EFI Platform Spec } \\
1.2\end{array}$ & UEFI & CONSORTIA & RAND \\
\hline OpenAL & $\begin{array}{l}\text { Foundation } \\
\text { Creative } \\
\text { Technology }\end{array}$ & COMPANY & $\mathrm{RF}$ & \multirow{3}{*}{$\begin{array}{l}\text { TCG EFI Protocol Spec. } \\
1.2 \\
\text { TCG Physical Presence } \\
\text { Interface Spec }\end{array}$} & UEFI & CONSORTIA & RAND \\
\hline \multirow{3}{*}{$\begin{array}{l}\text { OpenCL } \\
\text { OpenGL } 4.0 \text { Compaitbility } \\
\text { Profile Specification }\end{array}$} & Khronos & CONSORTIA & $\mathrm{RF}$ & & $\begin{array}{l}\text { Trusted } \\
\text { computing }\end{array}$ & CONSORTIA & RAND \\
\hline & \multirow[t]{2}{*}{ Khronos } & \multirow{2}{*}{ CONSORTIA } & $\mathrm{RF}$ & & Group & & \\
\hline & & & & TCP & IETF & CONSORTIA & RAND \\
\hline $\begin{array}{l}\text { OpenGL } 4.0 \text { Core Profile } \\
\text { Specification }\end{array}$ & Khronos & CONSORTIA & $\mathrm{RF}$ & Theora & $\begin{array}{l}\text { Xiph.Org } \\
\text { Foundation }\end{array}$ & CONSORTIA & $\mathrm{RF}$ \\
\hline OpenGL ES & Khronos & CONSORTIA & $\mathrm{RF}$ & TKIP & IEEE & SDO & RAND \\
\hline OpenGL SC 1.0 & Khronos & CONSORTIA & $\mathrm{RF}$ & TPM 1.2 Protection Profile & Trusted & CONSORTIA & RAND \\
\hline $\begin{array}{l}\text { OpenGL Shading } \\
\text { Language } 4.00 .7\end{array}$ & Khronos & CONSORTIA & $\mathrm{RF}$ & & $\begin{array}{l}\text { computing } \\
\text { Group }\end{array}$ & & \\
\hline Specification & & & & TSR jack $3.5 \mathrm{~mm}$ (PCXX & Intel & COMPANY & NA \\
\hline OpenKode & Khronos & CONSORTIA & RF & version) & & & \\
\hline OpenMAX & Khronos & CONSORTIA & $\mathrm{RF}$ & UDP & IETF & CONSORTIA & RAND \\
\hline OpenML & Khronos & CONSORTIA & $\mathrm{RF}$ & $\begin{array}{l}\text { UEFI Platform Initilization } \\
\text { Distribution Packaging }\end{array}$ & UEFI & CONSORTIA & RAND \\
\hline OpenSL/ES & $\begin{array}{l}\text { Khronos } \\
\text { Group }\end{array}$ & CONSORTIA & RF & Spec 1.0 & & & \\
\hline OpenVG & Khronos & CONSORTIA & $\mathrm{RF}$ & $\begin{array}{l}\text { UEFI Platform Initilization } \\
\text { Specification } 1.2\end{array}$ & UEFI & CONSORTIA & RAND \\
\hline OpenWF & Khronos & CONSORTIA & $\mathrm{RF}$ & UEFI Shell Spec 2.0 & UEFI & CONSORTIA & RAND \\
\hline $\begin{array}{l}\text { PCI Express Base } \\
\text { Specification } 2.0[\mathrm{x} 8, \mathrm{x} 16]\end{array}$ & PCI-SIG & CONSORTIA & RAND & $\begin{array}{l}\text { UEFI Specification } \\
\text { Version } 2.3\end{array}$ & UEFI & CONSORTIA & RAND \\
\hline PCI Local bus Spec 3.0 & PCI-SIG & CONSORTIA & RAND & Universal Audio & Microsoft & COMPANY & NA \\
\hline $\begin{array}{l}\text { PCI Local Bus } \\
\text { Specification } 3.0\end{array}$ & PCI-SIG & CONSORTIA & RAND & $\begin{array}{l}\text { Architec } \\
\text { UPnP }\end{array}$ & UPnP Forum & CONSORTIA & $\mathrm{RF}$ \\
\hline PCMCIA/PC Card & USB-IF & CONSORTIA & $\mathrm{RF}$ & USB & USB-IF & CONSORTIA & RF \\
\hline PGA-989 socket & Intel & COMPANY & NA & VC-1 (SMPTE 421M) & SMPTE & CONSORTIA & NA \\
\hline PGP (RFC 4880) & IETF & CONSORTIA & RAND & VCD ("White Book") & Various & CONSORTIA & NA \\
\hline PNG & $\mathrm{W} 3 \mathrm{C}$ & CONSORTIA & RF & VESA DDC2/E-DDC & $\begin{array}{l}\text { companies } \\
\text { VESA }\end{array}$ & CONSORTIA & RAND \\
\hline POP & IETF & CONSORTIA & RAND & VGA & IBM & COMPANY & NA \\
\hline Quicktime & Apple & COMPANY & NA & VOB & DVD Forum & CONSORTIA & NA \\
\hline RealVideo $3 \& 4$ & RealNetworks & COMPANY & NA & VP5 & & COMPANY & NA \\
\hline RJ-11 (TIA-968-A) & TIA & SDO & RAND & & Technologies & & \\
\hline RSS & Various & CONSORTIA & NA & VP6 & On2 & COMPANY & NA \\
\hline RSVP & IETF & CONSORTIA & RAND & VP8 & Google & COMPANY & NA \\
\hline RTMP & Adobe & COMPANY & RF & WAV & MSFT and & COMPANY & NA \\
\hline RTP & IETF & CONSORTIA & RAND & & IBM & & \\
\hline RTSP & IETF & CONSORTIA & RAND & WebGL - OpenGL ES 2.0 & Khronos & CONSORTIA & $\mathrm{RF}$ \\
\hline S/MIME & IETF & CONSORTIA & RAND & WIGIG 1.0 & Wireless & CONSORTIA & $\mathrm{RF}$ \\
\hline SATA & $\begin{array}{l}\text { Serial ATA } \\
\text { Int'l Org. }\end{array}$ & CONSORTIA & RAND & & Alliance & & \\
\hline SD & SD & CONSORTIA & RAND & WiMax (IEEE 802.16) & IEEE & SDO & RAND \\
\hline & Association & & & Wireless 802.11 [a/b/g/n] & IEEE & SDO & RAND \\
\hline SDL 1.3 & $\begin{array}{l}\text { open source } \\
\text { project }\end{array}$ & CONSORTIA & $\mathrm{RF}$ & Wireless HD 1.0 & $\begin{array}{l}\text { Wireless HD } \\
\text { Consortium }\end{array}$ & CONSORTIA & NA \\
\hline SDP & IETF & CONSORTIA & RAND & WMV & Microsoft & COMPANY & NA \\
\hline SDRAM & JEDEC & SDO & RAND & WSDL & W3C & CONSORTIA & $\mathrm{RF}$ \\
\hline SHA-1 (FIPS PUB 180) & NIST & SDO & NA & x.509 & ITU-T & SDO & RAND \\
\hline SIP & IETF & CONSORTIA & RAND & x86-64 Instruction Set & Intel/AMD & COMPANY & NA \\
\hline SmartMedia & Toshiba & COMPANY & NA & $\mathrm{XHCI}$ & Intel & COMPANY & NA \\
\hline SMTP & IETF & CONSORTIA & RAND & XML & $\mathrm{W} 3 \mathrm{C}$ & CONSORTIA & $\mathrm{RF}$ \\
\hline SOAP & W3C & CONSORTIA & $\mathrm{RF}$ & & & & \\
\hline SODIMM & JEDEC & SDO & RAND & & & & \\
\hline
\end{tabular}

